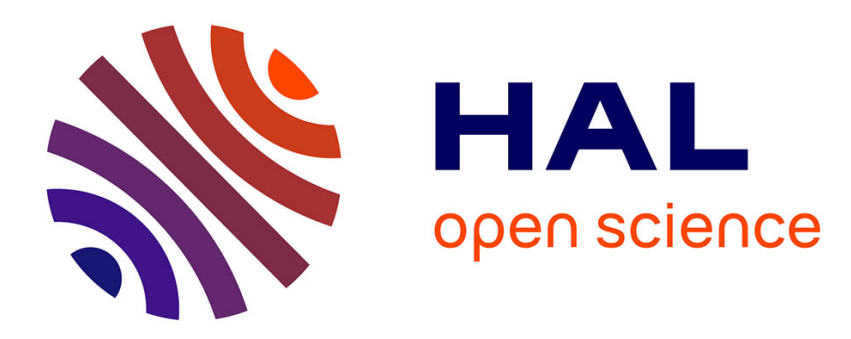

\title{
Why hayek is a Darwinian (after all)? Hayek and Darwin on social evolution
}

\author{
Alain Marciano
}

\section{To cite this version:}

Alain Marciano. Why hayek is a Darwinian (after all)? Hayek and Darwin on social evolution. Journal of Economic Behavior and Organization, 2009, 71 (1), pp.52. 10.1016/j.jebo.2007.04.005 . hal-00704680

\section{HAL Id: hal-00704680 \\ https://hal.science/hal-00704680}

Submitted on 6 Jun 2012

HAL is a multi-disciplinary open access archive for the deposit and dissemination of scientific research documents, whether they are published or not. The documents may come from teaching and research institutions in France or abroad, or from public or private research centers.
L'archive ouverte pluridisciplinaire HAL, est destinée au dépôt et à la diffusion de documents scientifiques de niveau recherche, publiés ou non, émanant des établissements d'enseignement et de recherche français ou étrangers, des laboratoires publics ou privés. 


\section{Accepted Manuscript}

Title: Why hayek is a Darwinian (after all)? Hayek and

Darwin on social evolution

Author: Alain Marciano

PII: $\quad$ S0167-2681(09)00056-0

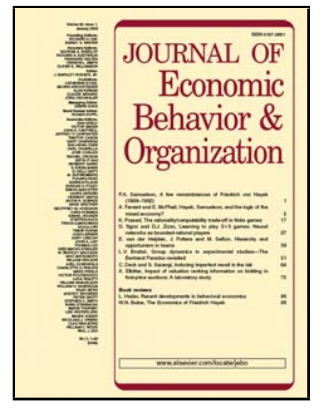

DOI: $\quad$ doi:10.1016/j.jebo.2007.04.005

Reference: $\quad$ JEBO 2328

To appear in: Journal of Economic Behavior \& Organization

Received date: $\quad 1-2-2007$

Accepted date: $\quad$ 26-4-2007

Please cite this article as: Marciano, A., Why hayek is a Darwinian (after all)? Hayek and Darwin on social evolution, Journal of Economic Behavior and Organization (2008), doi:10.1016/j.jebo.2007.04.005

This is a PDF file of an unedited manuscript that has been accepted for publication. As a service to our customers we are providing this early version of the manuscript. The manuscript will undergo copyediting, typesetting, and review of the resulting proof before it is published in its final form. Please note that during the production process errors may be discovered which could affect the content, and all legal disclaimers that apply to the journal pertain. 
Why Hayek is a Darwinian (after all)?

Hayek and Darwin on social evolution

Alain Marciano, Université de Reims Champagne Ardenne and EconomiX-Cachan$\mathrm{CNRS}^{1}$

\begin{abstract}
This article proposes to reassess Hayek's theory of cultural evolution in the light of Darwin's Descent of Man. It is shown that Hayek and Darwin refers to the same theory of human nature, which is borrowed from the founding fathers of political economy, Hume and Smith. Their respective conceptions of order, as well as the mechanisms and the product of evolution, are then the consequence of this theory of human nature.
\end{abstract}

\title{
JEL Classification A 11, B 52
}

Key-words Cultural evolution, Biological evolution, Darwin, Descent of Man, Hayek.

\section{Acknowledgement}

I would like to thank Stefano Fiori, Michael Ghiselin, Pierre Garouste, Evelyn Gick, Elias Khalil, Roger Koppl, David Sloan Wilson as well as two referees for remarks of earlier versions of this paper; remaining errors are mine. The paper was presented at the conference of the Society for the Development of Austrian Economics held during the Southern Economic Association annual conference, Charleston, SC, November 2006. I also acknowlege the support of the ICER and the Dipartimiento di Economia of the Università degli Studi di Torino.

1 Université de Reims Champagne Ardenne, Faculté des Sciences Economiques et de Gestion, OMI-EDJ, 57 bis, rue Pierre Taittinger, F-51096 Reims Cedex, France alain.marciano@univ-reims.fr 


\section{Introduction}

When he concludes the first edition of his Origin of Species by Means of Natuural Selection, a treatise on biological evolution, Charles Darwin suggests the possibility of using his theory to explain the evolution of human faculties and societies, or human and social phenomena: "In the distant future, I see open fields for far more important researches. Psychology will be based on a new foundation, that of the necessary acquirement of each mental power and capacity by gradation. Light will be thrown on the origin of man and his history" (1874 [1859], p. 424; emphasis added). Clearly, Darwin has not only the project to study the origins of a very peculiar species, man, and the evolution of human traits and faculties. Obviously, Darwin also believed that his theory on the origins of species can be generalised and applied to human beings. Actually, this has been emphasised, Darwin was rapidly ("in the year 1837 or 1838" (2005 [1887], p. 52) while he is writing the Origin of Species) "convinced that species were mutable productions" (2005 [1887], p. 52) and then he "could not avoid the belief that man must come under the same law" (2005 [1887], p. 52). However, such views were obviously challenging to what people of his time believed. Therefore, Darwin decided to behave cautiously in the exposition of his theories, considering "useless and injurious to the success of the book to have paraded without giving any evidence my conviction with respect to his origin" (2005 [1887], p. 52). Only when Darwin "found that many naturalists fully accepted the doctrine of the evolution of species", was it "to [him] advisable to work up such notes as [he] possessed and to publish a special treatise on the origin of man" (2005 [1887], p. 52). The treatise Darwin eventually published in 1871 is entitled the Descent of Man and Selection in Relation to Sex, and its purpose is to show "that man must be included with other organic beings in any general conclusion respecting his manner of appearance on this earth" (Darwin, 1988, p. 1). In other words, the book is indeed written with the important objective to complement the theses of the Origin of Species.

Although the Descent of Man obviously occupies a non-negligible place in Darwin's theoretical framework, the book has not been frequently referred to (quoted, cited or even mentioned) by economists who view Darwin only as the author of one major book, 
a biologist whose concepts were used by others to develop theories of social evolution rather than as a biologist who indeed attempted to develop his own theory of social evolution. As a consequence, the focus has always essentially been put upon the Origin of Species, the Descent of Man being left aside (Marciano, 2007). The debates about Darwin and how his insights could help the establishment of a theory of social evolution were, and still are, methodological, epistemological or ethical: the questions that are thus asked relate to the possible transfer of concepts and mechanisms from biology to social sciences, from nature to human societies.

One of the most important (even if controversial) scholars with regard to social and cultural evolution, Friedrich Hayek significantly adopts the same attitude towards Darwin. Nothing indeed suggests that Hayek refers to the social evolutionist who wrote the Descent of Man. On the contrary, Hayek almost undoubtedly considers Darwin as a biologist only. He therefore equates Darwinism with biology and a Darwinian theory with a biological theory of evolution as when he speaks of "the Darwinian or biological theory of evolution" (1988, p. 24). This has, in Hayek's views, two implications. First, Darwinian explanations of social evolution, because they are based on a biological theory, belong to social Darwinism, a doctrine with which Hayek does not want to be associated and that he criticises, in particular under the form of the theories developed by Bagehot and Spencer (see for instance, Hayek 1958, pp. 243-244). Then, second, Hayek rejects Darwin and Darwinism because he considers that social evolution and biological evolution do not involve the same mechanism. For Hayek, in effect, social evolution rests upon the transmission of acquired characteristics while biological evolution does not. The inheritance of acquired characteristics is usually viewed as one and even of the "first meaning of Lamarckism" (Hodgson and Knudsend, 2006, p. 343; see also, in particular, Hodgson, 2001, or Hull, 1982) and, accordingly, the difference that exists between Darwin's and Lamarck's theories of evolution. This is also the criterion that Hayek uses. He thus insists that " $[t]$ he Mechanism of Cultural Evolution is Not Darwinian” (1988, p. 23; emphasis added), by which he means not biological, but “cultural evolution simulates Lamarckism” (1988. p. 25; emphasis in original).

Whether Hayek's theory of social evolution is indeed Lamarckian or Darwinian or 
both has been debated (see among others, Birner, forthcoming, 2007; Hodgson, 200;

Khalil, 1996; Witt, 1995 and 1994). Beyond the answer itself, what is important to note is that commentators have always tried to compare Hayek's theory of cultural evolution with a biological (Lamarck's or Darwin's) theory of evolution. No comparison has ever been made with Darwin's theory of social evolution. This is the purpose of this paper: to compare Hayek's theory of cultural evolution with the theory of social evolution exposed by Darwin in his Descent of Man and to show that, in that case, it is possible to conclude that Hayek's theory of social evolution is Darwinian.

Our demonstration develops in two stages. First, we argue that the two theories rest on the same ontological or philosophical basis, that of the Scottish Enlightenment (section 1), and, second, that they are based on the same principles: a similar target and mechanism of selection (section 2).

\section{The Scottish Enlightenment as a common background}

The writings of the classical political economists undoubtedly form the "background" (Caldwell, 2000; see also Dupuy, 2004) that gives Hayek's theory of cultural evolution its meaning. Thus, Hayek has always insisted that one should not forget that Darwin inherited the important concepts upon which rests his theory of biological evolution from classical political economists: "The idea of biological evolution stems from the study of processes of cultural development” (1988, p. 24) ${ }^{2}$. Hume, Smith, Ferguson and Stewart were, in Hayek's views, "Darwinians before Darwin" and, more specifically, "Hume may be called a precursor to Darwin in the field of ethics" (Hayek, 1991 [1967a], p. 107). Now, the reasoning Darwin follows in the Descent of Man has its roots in the same tradition. In effect, in the Descent of Man, the references to the classical political economists are much more frequent than in the Origin of Species. Darwin then interestingly refers to Hume's Treatise on Human Nature (1992 [1739-1740]) and Smith's Theory of Moral Sentiments (1976 [1759]). Thus, both Darwin and Hayek utilise the same theory of human nature when they reflect on the evolution of human

2 See the analyses by Gordon, (1991), Depew and Weber (1995), and Schweber (1977 and 1980). 
societies.

\subsection{Reason, between abstraction and imitation}

Hayek and Darwin acknowledge the fact that human beings are granted a specific capacity that can be qualified as "reason". Hayek claims that he is a "rationalist," and, on his side, Darwin states that "of all the faculties of the human mind, it will, I presume, be admitted that Reason stands at the summit" (1988, p. 292). Thus, Hayek and Darwin undoubtedly believe in reason and rationality. However, they both retain a specific and similar definition of reason that makes their rationalism specific, in particular when compared to what could be considered as a standard, rational version of rationalism. In effect, both Hayek and Darwin adopt the view that can also be found in the writings of the founders of classical political economy, Hume and Smith, and oppose to the rationalist tradition usually associated with the French philosopher René Descartes. In other words, to grasp Hayek's and Darwin's views on reason, one has to refer to the opposition that exists between Descartes and Hume or Smith.

For Descartes, human beings are granted with a specific (specifically human because animals do not benefit from such an aptitude to reason) and particularly powerful capacity that is named "reason". The latter constitutes the origins, the point of departure, of knowledge; in other words, the source of knowledge does not lie in the external world but within the human mind. Thus, from a Cartesian rationalist perspective, human reason is independent from the external world: it does not simply organise and structure the information transmitted through the senses but also identifies misleading information and separates it from objective or "true" information and, above all, creates knowledge in the absence of any sensitive experience of the world. Reason is, according to Descartes, an obviously constructivist capacity. By contrast, some philosophers (including, among others, Condillac, Hume and Smith) develop a sensualist theory of human nature in which the central cognitive role is no longer devoted to reason but to the senses (Marciano, 2005 and 2006). Thus, the primary material upon which human knowledge is based lies in the environment, the impressions, data, or information that are conveyed through the senses to the human 
mind. Then, once data have been perceived, reason combines them into meaningful knowledge. What is noticeable therefore is that human reason is a limited or bounded capacity: it entirely depends on and thus cannot go beyond what has been gathered from the external world. To be more precise, individuals do not perceive independent and isolated impressions. Rather, the mind stores sequences of impressions (or cognitive sequences) that will then make the perception of new impressions possible. Thus, perception is past- or path-dependent: the capacity to perceive objects increases with but also depends on the number of perceptions. Reciprocally, past-perceptions play the role of a filter for future ones: an impression is perceived if and only if it fits into the set or pattern of already perceived impressions.

Hayek strongly criticises and opposes Descartes and Cartesianism under its many forms for being a constructivist theory of human rationality; it assumes that human beings benefit from a broader (too strong and powerful) reason than they actually do. More precisely, Hayek associates Descartes and Cartesianism with a false version of rationalism (Caldwell, 2000, p. 7; Boettke, 1990; Horwitz, 2000) ${ }^{3}$. In contrast, there exists a "true" version of individualism, and according to Hayek, it corresponds to the theory of human nature developed by the founders of classical political economy. In effect, their theory of human nature is similar to Hayek's philosophy of mind and his related theory of perception. Our mind is supposedly made up of abstract categories that serve to interpret, select, and then classify incoming information. Therefore, abstract categories precede and make possible, temporarily and logically, conscious thinking and our aptitude to form explicitly more complicated abstractions (Hayek, 1977, for instance); one should not confuse the abstract schemata that result from experience and allow perception with abstract scientific theories. As a consequence, the abstract schemata that compose the human mind depend on the experience previously accumulated: "every sensation, even the 'purest', must therefore be regarded as an interpretation of an event in the light of the past experience of the individual or the

3 Caldwell insists that Hayek's social philosophy, and also his theory of cultural evolution, rests on the distinction he makes between "individualism true" and "individualism false" (2000, p. 7). 
species" (1952, p. 16; see also 1989, pp. 35-49; and 1988). Therefore, the differences that indeed exist between the cognitive capacities of adults, children, or animals are only a matter of quantity of accumulated experience. No qualitative differences distinguish animals, children, and adults. They all possess the capacity to perceive the external world through abstract categories:

"The baby and the animal certainly do not live in the same sensory world in which we live. But this is so, not because, though their 'sense data' are the same, they have not yet been able to derive from them as many abstractions as we have done, but because of the much thinner net of ordering relations which they possess - because the much smaller number of abstract classes under which their subsume their impressions makes the qualities which their supposedly elementary sensations possess much less rich." (1989, p. 44)

On his side, Darwin does not explicitly oppose to the Cartesian tradition of rationalism. No quotation nor mention of or explicit reference to Descartes can be found in Darwin's writings. But this may not prove anything. More significant to understand the probably implicit opposition to the theories of Descartes is the fact that Darwin in effect clearly locates his works in a tradition that is opposed to Descartes, the Scottish Enlightenment tradition of Smith and Hume. Thus, Darwin significantly claims that as soon as human beings as well as animals are able to classify what they perceive through their senses (the impressions they receive from the external world) into existing categories, they are able to conceive general ideas. In this regard, there are no differences between man and animals. They both perceive their environment through abstract categories, "general concepts," that help them to identify or recognise "patterns". He thus notes that "the greatest stress seems to be laid on the supposed entire absence in animals of the power of abstraction, or of forming general concepts" (1988, p. 296). However, "when a dog sees another dog at distance, it is often clear that he perceives that it is a dog in the abstract; for when he gets nearer his whole manner suddenly changes if the other dog be a friend" (1988, p. 296). He thus departs from rationalism (in which the existence of rational reason marks the difference between man and animals) and accepts the idea that "there is no fundamental difference between man 
and the higher mammals in their mental faculties" (1988, p. 296) ${ }^{4}$. Furthermore, as a previous quotation shows, Darwin significantly illustrates his description of how human reason functions by examples of the behaviours of animals (1988, pp. 292-294). Then, if there are differences, and indeed there are, between man and higher mammals, they depend on the on the amount of accumulated experience. He thus notes that,

no doubt, as Mr. Wallace has argued, much of the intelligent work done by man is due to imitation and not to reason; but there is this great difference between his actions and many of those performed by the lower animals, namely, that man cannot on his first trial, make, for instance, a stone hatchet or a canoe, through his power of imitation. He has to learn his work by practice. (1988, pp. 288-289; emphasis added)

In other words, Darwin claims, the repetition of purposeful actions allows human beings, and higher mammals as well, to acquire a certain experience of the relationships that exist between events. Then, practice and experience give birth to abstract classes that in turn breed more experience and increase the individual's capacity to reason. Therefore, to claim, as Darwin does, that reason stands at the "summit" of human faculties does not mean that this faculty stands "above" other human faculties.

In this view, Hayek and Darwin seemingly share a similar conception of reason: this

4 What can be called "evolutionist continuity" between man and animals is a controversial issue, yet Darwin viewed this continuity as a key element that could guarantee the consistency of the theories presented in the Origin of Species and the Descent of Man. Thus, in his autobiography, he writes, "As soon as I had become, in the year 1837 or 1838 , convinced that species were mutable productions, I could not avoid the belief that man must come under the same law. Accordingly I collected notes on the subject for my own satisfaction, and not for a long time with an intention of publishing" (year, p. 131). Man was then "a leitmotiv" (Herbert, 1971, p. 197) and "an issue of its own merit" (Herbert, 1971, p. 197; emphasis added) for Darwin since 1837, thirty-four years prior to the publication of the Descent of Man, when he filled his transmutation notebooks (from 1837 to 1841). Why is it so? The importance of a theory of human behaviour for Darwin "simply" rests in the possible generalisation of his theory of biological evolution. Indeed, this early conviction indicates both his optimism and satisfaction "about the general prospects ... and ... the explanatory powers of his theory" (Herbert, 1971, pp. 201-2). The confidence thus gained led him to raise "questions concerning the evolution of instincts, emotions, language and intelligence" and to ask "how one can explain sociability and the evolution of human societies and their institutions" (Schweber, 1977, p. 232). 
capacity is not the cause of knowledge and perception of the outside world; it rather results from the fact that human beings (and animals) receive perceptions from their environment. Human beings do not construct a priori speculative and independent abstract categories about the world. To the contrary, these categories result from being part of the world. To put it in other words, cognitive processes and the acquisition of knowledge result from participation in the world,rather than in speculation about the world as it is in Descartes' perspective (see Livingston, 1991, on the difference between 'participative' and 'speculative' knowledge). Reason thus results from being part of the world; reason results from the experience that human beings draw from their environment and, therefore, from the use and exercise of other capacities and faculties ${ }^{5}$.

Then, another question arises. Each individual subjectively perceives his or her environment. Therefore, the abstract classes that result from individual experience are also personal. Reason depends on the private, personal and subjective, accumulated experience. How does dispersed and subjective experience lead to harmonised knowledge?

\subsection{Social and moral instincts and human nature}

The perspective adopted by the founders of classical political economy, that is the assumption of a non-constructivist rationalism, necessarily implies that civil societies were not created by a social contract, or to put it differently, the idea that human beings could have given birth or created, instrumentally and purposefully, their societies is incompatible with the theoretical framework Hume and Smith adopt. In effect, individuals are not able to envisage and build institutions that they have not experienced, so institutions actually exist because they have always existed. In effect, in contrast to what individualist theorists (in particular social contract theorists like Hobbes) have argued, human beings never lived isolated and separated from others;

5 Significantly, Darwin describes reason after having described the other mental faculties, namely "attention" (1998 b, p. 291), "memory" (1998 b, p. 291), "imitation" (1998 b, pp. 291-292) and "imagination" (1998 b, p. 292). The order reveals that reason does not replace but completes other human faculties. Reason can only exist after other faculties have developed. 
they did not rationally choose to live with others in social groups, but have always lived in social states. If a state of nature ever existed, it never resembled to what Hobbes describes. On the contrary, for Hume, the "very first state and situation" of man is a "social state" in which "Cordial affection, compassion, sympathy, were the only movements, with which the human mind was yet acquainted" (1992 [1739-1740], p. 494). Sociability is not acquired but innate or rather, as both Hayek and Darwin claim, instinctive. On his side, Hayek argues that the model Hobbes proposed to explain the origins of societies that considers individualism and isolation as the primary form of life is "mythical" : "the primitive individualism described by Thomas Hobbes is ... a myth" (1988, p. 20). Similarly, Darwin insists that the first stages of human or animal life were social: "Every one will admit that man is a social being" (1988, p. 76). In both cases, the explanation given to justify the elementary fact of social life refers to instincts. Hayek claims, "The savage is not solitary, and his instinct is collectivist" (1988, p. 20).

Instincts thus form the "cement" of primary and elementary social groups, first of all because of their biological nature. They exist before any other faculty and, accordingly, make the development of mental faculties possible. To some extent, this means that original instincts do not disappear. They develop, grow, and eventually change, turning into something more complex. This is indeed a typical feature of the evolutionary perspectives that Hayek and Darwin adopt, and this is consistent with the evolutionary continuity that exists between man and animals: human beings never lose their natural, and thus biological, origins. In fact, evolution does not imply or mean that instincts will eventually disappear, but their role changes and the number of behaviours driven by instincts progressively decrease with evolution while the role of reason and experience complementarily increase. However, Darwin is clear about the fact that the presence (or lack) of instincts cannot be used as a criterion to mark a difference between man, higher animals, and lower animals. On his side, Hayek also emphasises that even in open societies, there remains a part of each individual that react as a primary man, as a savage, and "still regards as good what was good in the small group" (1977, p. 149).

Interestingly, the last quotation reveals that instincts play a social role (sociability rests on instincts), but they also play an important role in interactions with others 
because of their moral dimension. In other words, instincts not only allow human beings to coordinate their activities, but they also affect the way they behave. From this perspective, it seems that both Darwin and Hayek envisage human interactions as having a twofold dimension, based on instincts and morality. In other words, individual behaviours and interactions are not only immediately and directly instinctive, but they also have a moral dimension. The two aspects cannot be separated and even, instincts and morality reinforce each other. First, sociability gives birth to morality: "any animal whatever, endowed with well-marked social instincts [...] would inevitably acquire a moral sense or conscience" (Darwin, 1988, p. 304) Reciprocally, morality breeds sociability. More precisely, the very existence of morality makes social interaction possible and allows the development of higher faculties such as reason and intelligence. Hayek writes,

Man is not born wise, rational and good, but has to be taught to become so. It is not our intellect that created our morals; rather, human interactions governed by our morals make possible the growth of reason and those capabilities associated with it. (1988, p. 21)

Darwin provides a specific explanation to the link that exists between morality and sociality. He thus argues that the moral sense that characterises human beings takes the form of sympathy, a concept that he explicitly links to Smith and "the excellent first chapter of [his] Theory of Moral Sentiments" ". Thus, sympathy "forms an essential part of the social instinct, and is indeed its foundation-stone" (1988, p. 304). However, evolution transforms (even if it does not suppress them) moral sentiments and instincts, modifying their role by comparison to the role played in primitive societies. Therefore,

6 Darwin's views on the role and importance of sympathy changed. In his notebooks, Darwin notes: "hence sympathy very unsatisfactory because does not like Burke explain pleasure" (notebook M, 108, August 1838, in Gruber, 1974, p. 286). Then, in the Descent of Man, he stresses, "Adam Smith has formerly argued [...] that the basis of sympathy lies in our strong relentiveness of former states of pain and pleasure. Hence, «the sight of another person enduring hunger, cold, fatigue, revives in us some recollection of these states, which are painful even in idea». We are thus impelled to relieve the sufferings of another, in order that our own painful feeling may be at the same time relieved. In like manner we are led to participate in the pleasures of others" (1988, p. 308). 
the functioning of what Hayek names "large societies" and Darwin "civilised societies" is different than that of primitive groups. In large or civilised societies, instincts may play a role in the interactions of friends and acquaintances. However, intincts )moral sentiments and sympathy) play a less important role when individuals interact with strangers. More precisely, in non-repeated interactions or when one interacts with someone else for the first time, calculus replaces instincts. This certainly does not mean that altruism is absent or that it disappears in interactions with strangers. In these circumstances, human behaviour no longer rests on moral sentiments but engages instrumentally our reason. This is the major difference with interactions that take place in small goups or among acquaintances that are instinctive or institinctively moral; they involve no calculus, no instrumental reason.

However, even if Darwin and Hayek seem to consider the moral role of instincts (or the role of moral sentiments) important, they do not use the same words to describe the nature of moral relationships between human beings. Darwin utilises the concept of sympathy, a concept that Hayek, quite surprisingly with regard to his debt towards the founders of political economy, never employs. Rather, he describes moral relationships in terms of "altruism". Is it only a matter of semantics, or are there conceptual differences between sympathy and Hayek's altruism? The question is all the more important since sympathy differs from altruism and egoism. Hume and Smith do not equate sympathy with altruism and do not consider that sympathy excludes egoism ${ }^{7}$. In other words, egoist behaviours remain possible even in a world in which sympathy supposedly characterises human nature. In fact, sympathy and egoism are complementary: when sympathy ceases to operate, egoism (or altruism) can take place ${ }^{8}$.

7 Adam Smith begins the Theory of Moral Sentiments by stating that an individual may feel sympathy and, at the same time, be selfish: "How selfish soever man may be supposed there are evidently some principles in nature which interest him in the fortune of others, and render their happiness necessary to him, though he derives nothing from it except the pleasure of seeing it" (1976 [1759], p. 9).

8 "Sympathy, however, cannot ; in any sense, be regarded as a selfish principle [...] That whole account of human nature, however, which deduces all sentiments and affections from self-love, which has made so much noise in the world, but which so far as I know, has never yet been fully distinctly explained, seems to me to have arisen 
This can be explained by the fact that sympathy only takes place among family members, close friends or acquaintances (see for instance Hume, 1992 [1739-1740], p. 534). This is one of the features that Darwin accepts and includes in his analysis: "sympathy is directed solely towards the members of the same community, and therefore towards known, and more or less beloved members, but not to all the individuals of the same species" (1988, p. 309). This is also a feature that, in Hayek's view, characterises altruism or moral sentiments that individual necessarily posses and feel towards the other members of the small groups to which he or she belongs. Hayek characterises the moral bonds that unite individuals in small groups as "a kind of 'moral socialism"' (1977, p. 91) and, most interestingly, claims that the moral sentiments that links individuals are "inherited or perhaps even innate moral emotions" (1977, p. 91); they are the consequence of "deeply ingrained instinct[s]" (1977, p. 91).

Thus, altruism and sympathy share, beyond their differences, the features to be both instinctive and to operate in small groups. This aspect plays a decisive role from the perspective of a theory of social evolution. Let us now turn to the analysis of Hayek's and Darwin's respective theories of cultural evolution.

\section{The mechanisms of selection}

In the theories that he develops in the Origin of Species and in the Descent of Man, Darwin utilises a principle of selection to explain evolution, but (and this is the reason why it is possible to speak about a theory of cultural evolution) the mechanism of selection does not function in the same way in the two areas of nature and culture. Darwin adapts the mechanism of selection to the domain in which his theory applies. In a similar perspective, Hayek seeks to demonstrate that a biological theory of evolution can possibly be used as a model to understand the evolution of institutions. Certainly, there are differences between biological evolution and social or cultural evolution. However, in both cases, evolution can be described as "a process of continuous adaptation to unforseable events, to contingent circumstances which could not have

from some confused misapprehension of the system of sympathy" (Smith, 1976 [1759], p. 317). 
been forecast" (Hayek, 1988, p. 25). Social order, just like biological order, then follows the same evolutionary logic: there is no global purpose that guides evolution. This common element can be used as a starting point to explain the use by Darwin and Hayek of the same mechanism of selection to explain social evolution (2.1). However, culture differs from nature. To take into account these differences, both scholars propose a theory in which the group is the target of the process of selection (2.2). The

process of cultural selection that then takes places at the group level mostly consists of a transmission of acquired characters (2.3) that involves individuals but rests on imitation (2.4).

\subsection{The principle of selection}

In the works he devotes to cultural evolution, Hayek frequently includes references to biology. The reason is straightforward: although there are differences (they will be discussed later) between nature and culture and the process of evolution in the two spheres, there also exist similarities. More than analogies that would allow superficial comparisons, Hayek claims that social evolution "follows in many respects the same pattern as biological evolution", that cultural evolution "looks very much like biological evolution" because "it also rests on a sort of natural selection" (1989, p. 292). In other words, biological and cultural evolution "both rely on the same principle of selection: survival or reproductive advantage. Variation, adaptation and competition are essentially the same kind of process, however different their particular mechanisms, particularly those pertaining to propagation" (Hayek, 1988, p. 26).

Similarly, Darwin's analysis of social evolution as presented in the Descent of Man also assumes an evolutionary continuity that exists between nature and culture. Even if Smith's Theory of Moral Sentiments and Hume's Enquiry on the Principles of Morals are referred to in the course of the exposition of his theory of social evolution, "Malthus's" struggle for life and even Spencer's survival of the fittest are nonetheless not absent from the theory that Darwin develops. This is not surprising. In effect, one should not forget that Darwin wanted to apply the concepts he used in his theory of biological evolution to model social evolution. In other words, his purpose was to 
describe the evolution of moral, mental and intellectual human faculties in terms of natural selection. Darwin thus frequently reminds his reader that one cannot explain the evolution of man and social faculties without a reference to natural selection and struggle for life: "I have now endeavoured to shew that some of the most distinctive characters of man have in all probability been acquired, either directly, or more commonly indirectly, through natural selection" (1988, p. 47); or "The early progenitors of man must ... occasionally have been exposed to a struggle for existence, and consequently to the rigid law of natural selection" (1988., p. 39); and "Such social qualities [as sympathy, fidelity, and courage], ... were no doubt acquired by the progenitors of man in a similar manner, namely, through natural selection" (1988, p. 321). Therefore, Darwin claims, natural selection guides biological as well as cultural evolution. By contrast with other naturalists of his time, who nonetheless defended the explanation of the dynamic evolution of social order based on a principle of selection, Darwin is one of the few to demonstrate that natural selection does not stop to operate at the frontier of the cultural sphere.

However, culture is not the extension of nature. Continuity, or the lack of rupture between culture and nature, does not mean that the exactly same mechanisms apply in the two spheres. Both Darwin and Hayek adopt a perspective in which natural selection does not suffice to explain the entire and complex phenomenon of social evolution.

\section{2. Social evolution and group selection}

The first very important difference that exists between cultural and biological evolution concerns the target of selection. Thus, although the same principle ("natural selection") applies in culture and in nature, competition or "struggle-for-life" does not take place between the same entities in nature and in culture. In this view, the most noticeable feature of Hayek's and Darwin's theories is that cultural evolution is modelled as a process of group selection rather than a process of individual selection. Therefore, the individual is no longer viewed as the target of selection, or in still other words, individuals no longer bear the reproductive advantage as in biological selection.

On his side, it is now admitted that Hayek (and this aspect of his theory has been the 
subject of many discussions) indeed proposes a theory of social evolution in which groups play a decisive and crucial role. In fact, as shown in particular by Caldwell (2000), Hayek "explicitly added the mechanism of group selection to his description of cultural evolution" in the late $1960 \mathrm{~s}^{9}$, then it became an increasingly prominent theme in Hayek's writings about social evolution (Caldwell, 2000; see also Angner, 2002; Steele (1987), lasting until The Fatal Conceit in the 1980s. There are not many direct and explicit references to "group selection" in Hayek's writings. Hayek first mentioned the necessity to refer to groups in an explanation of social evolution, his "first articulation of the notion of group selection" (Caldwell, 2000, p. 15), in 1967 when he noted that

For the understanding of animal and human societies the distinction is particularly important because the genetic (and in great measure also the cultural) transmission of rules of conduct takes place from individual to individual, while what may be called the natural selection of rules will operate on the basis of the greater or lesser efficiency of the resulting order of the group. (Hayek, 1967, p. 67; emphasis in original)

According to Caldwell (2000, p. 16), Hayek first mentions "group selection" explicitly in a footnote: "Although the conception of group selection may now not appear as important as it had been thought after its introduction [...] there can be no doubt that it is of the great importance for cultural evolution" (Hayek, 1979, p. 202, note 37). While aware of the limits of group selection explanations in biology, Hayek insists that this is one of the major differences that exist between cultural selection and biological selection: "whether group selection also operates in biological evolution remains an open question - one on which my argument does not depend" (1988, p. 25). He furthermore wrote that "cultural evolution is founded wholly on group selection" (Hayek, 1984, p. 318) or that "cultural evolution operates largely through group selection" (1988, p. 25).

About one hundred years before Hayek wrote these words, another biologist, namely Darwin, also built a theory of social evolution in which selection operates at the group

$9 \quad$ Precisely when group selection was attacked by Hamilton (1964a and 1964b) and Williams (1966). 
level. Thus, it can be argued, as Borello for instance does, that "some form of group selection was indeed a part of his original theory" (2005, p. 43); in that case, group selection was already used in the Origins of Species and more specifically in the part devoted to social insects. At least, it can be claimed that Darwin "resolutely opposed group selection in the non-human world", but "when it came to our own species, Darwin ... "became a group selectionist" (Ruse, 1980, p. 626). In effect, Darwin's group selectionism is explicitly at the core of his analysis of how human faculties evolve, that is, in the Descent of Man. Thus,

with strictly social animals, natural selection sometimes acts on the individual, through the preservation of variations which are beneficial to the community [...] With the higher social animals, I am not aware that any structure has been modified solely for the good of the community $[. .$.$] In regard to certain mental powers the case [\ldots]$ is wholly different; for these faculties have been chiefly, or even exclusively, gained for the benefit of the community, and the individuals thereof have at the same time gained an advantage indirectly. (1988, p. 285-286; emphasis added)

Furthermore,

A tribe including many members who, from possessing in a high degree the spirit of patriotism, fidelity, odedience, courage, and sympathy, were always ready to aid another, and to sacrifice themselves for the common good, would be victorious over most other tribes. $(1988$, p. 322)

Therefore, quite interestingly, Darwin focuses not only on the group as the target of selection, but also draws the most immediate and important consequence of this assumption: social selection is made possible because individuals are ready to sacrifice themselves for the benefit of the group.

\subsection{The transmission of acquired characteristics}

A second important, and paradoxical, feature of the theories of social evolution that were proposed by Darwin and Hayek that has to be investigated is the conservation or transmission of acquired characteristics. Usually, the possible transmission of acquired characteristics that obviously happens in human societies is assumed to be typical of Lamarck's theory rather than that of Darwin. Then, it cannot be Darwinian and should 
not be found in a Darwinian theory of evolution, yet both scholars envisage social and cultural evolution as a process in which the traits and practices that have been acquired can be transmitted to the other members of the group and then to other groups.

Hayek thus explains that "although biological theory now excludes the inheritance of acquired characteristics, all cultural development rests on such inheritance characteristics in the form of rules guiding the mutual relations among individuals which are not innate but learnt" $(1988$, p. 25$)$. That could be problematic to claim that Hayek's theory is Darwinian from the perspective of a comparison with Darwin's theory of biological evolution. However, the problem disappears if one refers to Darwin's Descent of Man. In effect, Darwin claims that intellectual and moral faculties are partly the product of the effects of natural selection and of learning and habit and, therefore, are partly inherited. Thus, he notes that "the intellectual and moral faculties of man ... are variable; and we have every reason to believe that the variations tend to be inherited" (1988, p. 89), and "The greater intellectual vigour and power of invention in man is probably due to natural selection, combined with the inherited effects of habit" (1988, p. 372); or "It is not improbable that after long practice virtuous tendencies may be inherited" (ibid., p. 376). These are but two references to "inheritance". The Descent of Man seems to be entirely built on two forces, natural selection and the transmission of acquired characteristics.

\subsection{Cultural selection, groups and individuals}

Theories of cultural selection in which the target is the group and acquired characters are transmitted have been criticised in economics as well as in biology for being unable to face problems of incentives and free riding: why would individuals accept sacrificing themselves for the group? Why do individuals innovate if their innovation benefits others first, and how and why do these innovations spread (are transmitted) from one individual to others and then from one group to others? Many have stressed how contradictory group selectionism could be from the perspective of supposedly individualist approaches such as Hayek's and Darwin's (see in particular Gray, 1984, pp. 52-53; Vanberg, 1886, 1994; Steele, 1987; Hodgson, 1991, 1993; Witt, 1993). In these 
views, the way that practices and traits are invented and transmitted from one individual to others and then from one group to others is hardly understandable. Two types of answers can be put forward to answer these criticisms.

First, group selection does not evacuate individuals from social evolution. In effect, group selection is "not incompatible with methodological individualism, once it is recognized that methodological individualism does not depend upon individual organisms being the (sole) unit of selection" (Whitman, 1998, p. 62). Social evolution, as described by Hayek and Darwin, thus involves two complementary levels, the lower individual and the higher group level (on this point see Garrouste, 1999). More precisely (this is of great importance), a hierarchical relationship links these two levels of selection, individuals and the groups to which they belong, the former being the necessary condition for the latter to develop. For instance, Gick and Gick (2001) have stressed that in Hayek's theory of social evolution, the role of individuals is necessary to innovate: it is not only that individual selection "is a process that operates on a subjectivist plane" (Gick and Gick, 2001, p. 157), but also that each individual's perceptions "are slightly different from already existing ones and hence lead to the creation of new rules" (ibid., p. 156, emphasis in original). On his side, Darwin, who does not enter into the details of the origins of innovation, nonetheless locates innovations at the individual level. However, innovation is not a consequence of incentives: it results from the differences that exist between subjective perceptions and subjective classification of external stimuli. This thus makes sense if viewed from the perspective of Hayek's, and Darwin's, theory of cognition described in the preceding section.

Second, one must not forget that the theories of social evolution we are discussing are rooted in the Scottish Enlightenment tradition ${ }^{10}$, in which individuals are not

10 As Steele claims, "Thus Hayek's repeated insistence on the importance of cultural group selection is part of his general case against what he regards as excessive reliance on reason" (1987, p. 173), but this is the reason that Hayek's theory of group selection assumes the legacy of classical political economy, precisely because he does not view individuals as rational beings. 
capable, because of the weakness of their reason, of evaluating or calculating the benefits of their actions. Therefore, they cannot rationally, deliberately and explicitly decide or choose to adopt a practice or even a "trait" (a moral quality) that is adopted by other individuals; such a calculus would require capacities that human beings do not have. Rather, and both Hayek and Darwin insist on this, the transmission of traits and practices among the members of a given group rest on learning. More specifically, learning through the imitation of the other members of the group is decisive in a process of cultural selection. The capacity to imitate others, as Hayek notes, the "ability to acquire skills by imitative learning", is "perhaps the most important capacity with which the human individual is genetically endowed, beyond innate response" $(1988, \text { p. } 21)^{11}$. On his side, Darwin claimed that "The principle of IMITATION is strong in man" (1988, p. 54), listed the "tendency to imitation" as one "of the faculties, which have been of inestimable service to man for his progressive advancement" (1988, p. 67), and accepted Wallace's statement that "much of the intelligent work done by man is due to imitation and not to reason" (1988, p. 51). More important is the fact that Darwin explicitly links imitation with the adoption of innovation within a group: "if some one man in a tribe ... invented a new snare or weapon, or other means of attack or defence, the plainest self-interest, without the assistance of much reasoning power, would prompt the other members to imitate him" (1988, p. 90).

Therefore, once an individual has innovated, his or her innovation may (or may not, if it is not adopted by the group) spread among the members of the group. Therefore, and this is the reason why one may speak of group selection, in both Hayek's and Darwin's views, a successful innovation has to be adopted within a group (this is a necessary condition) before being transmitted to (i.e. adopted by) other groups.

This raises a final problem that a theory of group selection has to deal with, namely the transmission of a trait or practice selected and adopted within a given group to other

11 It is interesting to note that the first time Hayek describes imitation (1967, p. 47), he explicitly refers to the chapter entitled "sympathetic imitation" written by Dugald Stewart, and one is reminded that when reading Stewart, Darwin became acquainted with Smith and sympathy. 
groups. In other words, how do the practices adopted within a group tend to displace those used in other groups? How do successful groups succeed and impose their practices on others? With regard to this question and Hayek's answers, commentators have noted how imprecise they were: "Hayek should be criticised ... for failing to incorporate additional processes of selection above the group level" (Hodgson, 1993, p. 177; see also, among others, Zywicki, 2000, p. 87; or Steele, 1987, pp. 173 ff).

Curiously, Darwin was not more precise in the Descent of Man, even if he seemingly attributed the same role to imitation between groups as within groups. It thus appears that for Hayek (and for Darwin as well), what seems to be important is the result of the process of social selection, namely that successful groups see their population increase, in absolute terms and also compared to other groups. Successful groups, in terms of evolution, are more populous than others and therefore wealthier (see, Hayek 1988, pp.120-22). Thus, population growth is the key to success in inter-group competition. The explanation Hayek gives parallels the one proposed by Darwin; the latter links the increase in population of one group with the transmission of innovative practices or traits:

We can see, that in the rudest state of society, the individuals who were the most sagacious, who invented and used the best weapons or traps, and who were best able to defend themselves, would rear the greatest number of offspring. The tribes, which included the largest number of men thus endowed, would increase in number and supplant other tribes. Numbers depend primarily on the means of subsistence, and this depends partly on the physical nature of the country, but in a much higher degree on the arts which are there practised. As a tribe increases and is victorious, it is often still further increased by the absorption of other tribes. (1988, p. 89)

Similarly, "If the new invention were an important one, the tribe would increase in number, spread, and supplant other tribes" (1988, p. 88), and "Nevertheless the more intelligent members within the same community will succeed better in the long run than the inferior, and leave a more numerous progeny" (1988, p. 90).

\section{Conclusion}

The purpose of this paper is to show that Hayek's theory of cultural evolution can 
indeed be considered Darwinian. To reach this conclusion, in contrast to the usual perspectives on Hayek and Darwin, we have compared Hayek's and Darwin's theories of social evolution. It then appears that both theories belong to the same philosophical or ontological tradition, that of the Scottish Enlightenment. Furthermore, they both take into consideration the specificities of cultural evolution with regard to biological evolution: both Hayek and Darwin consider that selection takes place at the group level, and both of them argue that acquired characteristics are transmitted. The latter element is interesting since it helps to clarify the differences that exist between Hayek and Darwin, on one side, and Lamarck, on the other side, the major difference being that Hayek and Darwin envisage the transmission of acquired characteristics from the perspective of spontaneous order where Lamarck views this feature as taking place in a teleological process.

\section{References}

Angner, E., 2002. The history of Hayek's theory of cultural evolution. Studies in History and Philosophy of Biological and Biomedical Sciences 33, 695-718.

Birner, J., forthcoming 2007. Popper's rethinking of evolution in the light of Hayek's theory of culture. Boston Studies, 272.

Boettke, P., 1990. The theory of spontaneous order and cultural evolution in the social theory of F. A. Hayek. Cultural Dynamics 3, 61-83.

Borrello, M. E., 2005. The rise, fall and resurrection of group selection. Endeavour $29,43-47$.

Caldwell, B., 2000. The emergence of Hayek's ideas on cultural evolution. Review of Austrian Economics 13, 5-22.

Darwin, C., 1874 [1859]. The Origin of Species by the Means of Natural Selection, New York: Appleton. 
Darwin, C., 1988 [1871]. The Descent of Man and Selection in Relation to Sex. London: Encyclopedia Britannica.

Darwin, C. 2005 [1887]. The Autobiography of Charles Darwin, New York: Barnes and Noble.

Depew, D. J., Weber, B. H., 1995. Darwinism Evolving: Systems Dynamics and the Genealogy of Natural Selection. Cambridge, MA: MIT Press.

Dupuy, J.-P., 2004. Intersubjectivity and embodiment. Journal of Bioeconomics 6, 275-294.

Garrouste, P., 1999. Is the Hayekian evolutionism coherent? History of Economic Ideas 7, 85-103.

Gick, E., Gick, W., 2001. F.A. Hayek's theory of mind and theory of cultural evolution revisited: Toward an integrated perspective. Mind \& Society 3, 49-162.

Gordon, S. 1991. The History and Philosophy of Social Science. London: Routledge.

Gray, J., 1984. Hayek on Liberty. New York: Blackwell

Gruber, H. E., 1974. Darwin on Man. A Psychological Study of Scientific Creativity together with Darwin's Early Unpublished Notebooks (transcribed and annotated by Paul H. Barrett), London: Wilwood House.

Hamilton, W.D., 1964a. The genetical origin of social behavior I. Journal of Theoretical Biology 7, 1-16.

Hamilton, W.D., 1964b. The genetical origin of social behavior II. Journal of Theoretical Biology 7, 17-52.

Hayek, F. A., 1952. The Sensory Order. An Inquiry into the Foundations of 
Theoretical Psychology. London: Routledge, Kegan Paul.

Hayek, F. A., 1958. Freedom, reason and tradition. Ethics 682, 29-245.

Hayek, F. A., 1967. Studies in Philosopohy, Politics and Economics. Chicago: University of Chicago Press.

Hayek, F. A., 1977. Law, Legislation and Liberty. Vol. 2, The Mirage of Social Justice. Chicago: University of Chicago Press.

Hayek, F. A., 1979 [1952]. The Counter-Revolution of Science. Studies on the Abuse of Reason. Indianapolis: Liberty Press.

Hayek, F. A., 1984. The origin and effect of our morals: A problem for science. In Nishiyama, C., Leube, K. R. (Eds.). The Essence of Hayek. Stanford, CA: Hoover Institution Press, 318-330.

Hayek, F. A., 1988. The Fatal Conceit: The Errors of Socialism. Chicago: University of Chicago Press.

Hayek, F. A., 1989. New Studies in Philosophy, Politics and Economics. London: Routledge.

Hayek, F. A., [1991] 1967a. The Legal and Political Philosophy of David Hume (1711-1776), In: Bartley, W. W. and Kresge S. (Eds.), The collected works of F. A. Hayek, Vol. III. Chicago: University of Chicago Press, 101-118.

Herbert, S., 1971. Darwin, Malthus and Selection. Journal of the History of Biology 4, 437-459.

Hodgson, G. M., 1991. Hayek's theory of cultural evolution: An evaluation in light of Vanberg's critique. Economics and Philosophy 7, 67-82. 
Hodgson, G. M., 1993. Economics and Evolution: Bringing Back Life into Economics. Cambridge: Polity Press.

Hodgson, G. M. 2001. Is social evolution Lamarckian or Darwinian? In: Laurent, J., Nightingale, J. (Eds.). Darwinism and Evolutionary Economics. Cheltenham: Edward Elgar, 87-118.

Hodgson, G. M., T. Knudsen. 2006. Dismantling Lamarckism: Why Descriptions of Socio-Economic Evolution as Lamarckian are Misleading. Journal of Evolutionary Economics, 16, 343-366.

Horwitz, S. G. 2000. From The Sensory Order to the Liberal Order: Hayek's NonRationalist Liberalism. Review of Austrian Economics, 13, 23-40.

Hull, D. L. 1982. The naked meme. In: Plotkin Henry C (ed) Learning, development and culture: essays in evolutionary epistemology. New York: Wiley, 273-327.

Hume, D. 1992 [1739-1740]. A Treatise of Human Nature. Buffalo: Prometheus Books.

Khalil, E. L. 1996. Friedrich Hayek's Darwinian theory of evolution of institutions:

Two problems. Australian Economic Papers 35, 183-201.

Livingston, D. W., 1991. Hayek as Humean. Critical Review 5, 159-177.

Marciano, A., 2005. Non-benevolence, sympathy and the proper role of government. From new political economy back to old political economy. Boettke, P., Medema, S. (Eds). The Economic Theory of Government: History of Political Economy Annual Supplement 37, 43-70.

Marciano, A., 2006. David Hume's model of man : Classical Political Economy as 
'Inspired' political economy.. Review of Social Economy 64, 369-386.

Marciano, A., 2007. Economists on Darwin's theory of human nature and social evolution. European Journal of the History of Economic Thought, 14, 681-700.

Ruse, M., 1980. Charles Darwin and group selection. Annals of Science 37, 615-630

Schweber, S. S., 1977. The origin of the Origin revisited. Journal of the History of

Biology 10, 229-316.

Schweber, S. S., 1980. Darwin and the political economists: Divergence of character. Journal of the History of Biology 13, 195-289.

Smith, A. 1976 [1759]. The Theory of Moral Sentiments. Indianapolis: Liberty Press.

Steele, D. R., 1987. Hayek's theory of cultural group selection. Journal of Libertarian Studies 8, 171-195.

Vanberg, V. V., 1986. Spontaneous market order and social rules: A critique of F.A. Hayek's theory of cultural evolution. Economics and Philosophy 2, 75-100.

Vanberg, V. V. 1994. Rules and Choice in Economics. London: Routledge.

Whitman, D. G., 1998. Hayek contra Pangloss on evolutionary systems.

Constitutional Political Economy 9, 45-66.

Williams, G.C., 1966. Adaptation and Natural Selection. Princeton: Princeton University Press.

Witt, U., 1993. Turning Austrian economics into an evolutionary theory. In:

Caldwell, B., Boehm, S. (Eds.). Austrian Economics: Tensions and New Directions.

Dordrecht: Kluwer, pp. 215-236.

Witt, U., 1994. Evolutionary economics. In: Boettke, P. J. (Ed.). Elgar Companion to 
Austrian Economics. Aldershoot: Edward Elgar, 540-548.

Witt, U., 1995. The theory of societal evolution: Hayek's unfinished legacy. In:

Birner, J., van Zijp, R. (Eds.). Hayek, Co-ordination and Evolution: His Legacy in

Philosophy, Politics, Economics and the History of Ideas. London: Routledge, 178189.

Zywicki, T. J., 2000. Was Hayek right about group selection after all? Review Essay of Unto Others: The Evolution and Psychology of Unselfish Behavior by Elliott Sober and David Sloan Wilson. Review of Austrian Economics 13, 81-95. 